\title{
Sensitization of Thianthrenium Salt for Cationic Polymerization of Epoxides
}

\author{
M. Sakho, X. Allonas*, C. Ley \\ Department of Photochemistry, CNRS, University of Haute Alsace, ENSCMu, \\ 3 rue Alfred Werner, 68093 Mulhouse Cedex-France. \\ xavier.allonas@uha.fr
}

\begin{abstract}
We evaluated the influence of sensitizers on the reactivity of a thianthrenium salt. Calculating the difference in free energy shows that the decomposition of the salt occurs through electron transfer mechanism. Photopolymerization efficiency was evaluated using real-time RTIR, showing that the sensitization process is effective and that its efficiency is governed by the photoinduced electron transfer reaction.
\end{abstract}

Keywords: cationic photopolymerization, photosensitizer, electron transfer

\section{Introduction}

Photoinitiated polymerization is an essential technique for many industrial applications such as UV-curing of coatings, printing inks and photoresist technology. Cationic photopolymerization possesses many advantages compared to the radical polymerization such as reduced shrinkage and insensitivity to the presence of oxygen. Diaryliodonium and triarylsulfonium salts with non-nucleophilic anions are widely used photoinitiators for cationic polymerization $[1,2]$. Diaryliodoniums were found to absorb strongly in the short-wavelength $220-250 \mathrm{~nm}$ UV region, and triarylsulfoniums exhibit absorption properties that are slightly shifted to the blue. Several strategies have been adopted by structural change of triarylsulfonium salts in order to expand their absorption spectrum, but with a limited success. By example the introduction of a 4-thiophenoxy chromophore on triarylsulfonium salts and further extensions of this strategy improved the sensitivity to near-UV light. Today mixtures of triarylsulfonium salts are supplied as solutions in propylene carbonate with UV absorption maxima about $300-310 \mathrm{~nm}[3,4]$.
However, the discovery of release of toxicologic aromatic hydrocarbons and undesirable odorous (diphenylsulfide as photodecom position product of sulfonium salts) had a dramatic effect in many applications. Therefore, to circumvent the adverse effects mentioned above, different research group started to develop new photoinitiators with similar characteristics, but without sulfonium salts drawback related to the toxicity of by-products.

The most appropriate way to reduce undesirable photoproducts of concern from triarylsufonium salts is to incorporate the aryl sulfonium group into a cyclic structure such as a thianthrene. This basic structure was used for the preparation of cyclic sulfonium salts. The recent development of thianthrenium salts used in cationic UV-curing can contribute to increase and diversify the application of this technology $[5,6]$. The process of photolysis of 5-Arylthianthrenium salts results in two ways: the first way generates cation-radicals capables of forming strong Brönsted acids by interaction with impurities. The second way 
lead to reversible cleavage between carbon-sulfur on the cycle thianthrenium giving the cation radical-radical pair $[5,7]$.

Although the onium salts exhibit relatively low absorption above $320 \mathrm{~nm}$, their spectral response can be extended into the near-UV and visible spectral regions by photosensitization process $[5,7]$. This contribution is needed to improve the efficiency of the photolysis process of the photoinitiator and consequently, generating a larger number of initiating species and producing an apparent acceleration of the rate of polymerization. Many aromatic hydrocarbons are able to sensitize the decomposition of iodoniums salts via electron transfer. However, most of the sensitizers are unable to react with conventional triarylsulfonium salts.

We investigated here the influence of some sensitizers on the reactivity of 9-(4-hydroxyethoxyphenyl) thianthrenium hexafluorophosphate $\mathbf{T T}^{+}$. The photopolymerization efficiency was evaluated using real-time FTIR. From the Gibbs energy of electron transfer, the reaction process was assessed.

\section{Experimental}

\subsection{Materials}

9-(4-hydroxyethoxyphenyl) thianthrenium hexafluorophosphate $\mathbf{T T}^{+}$was obtained from Lamberti (Esacure 1187). The cationic resin is 3,4-epoxycyclohexyl methyl-3,4-epoxy cyclohexane carboxylate R1 (UVR-6110, Dow). Phenothiazine (Ph), Thioxanthone (TX), Isopropylthioxanthone (ITX), 2-Chlorothio xanthone (2CTX), 9-Methyl anthracene (9MA), 9,10-Dimethyl anthracene (9,10DMA), 9,10-Diethoxy anthracene (9,10DEA) were used as photosensitizers (PS). The compounds are shown in Scheme 1.

\subsection{Photopolymerization experiments}

The liquid resin was applied onto a $\mathrm{KBr}$ crystal with a thickness of about $8 \mu \mathrm{m}$. The kinetic parameters were measured using real time FTIR spectroscopy $[8,9]$ by monitoring the decrease of the IR band characteristic of the reactive functional group at $750-790 \mathrm{~cm}^{-1}$.

During the experiments, the formulation is exposed to UV-visible light of a Xe-Hg lamp (Hamamatsu, L8252, 150W).
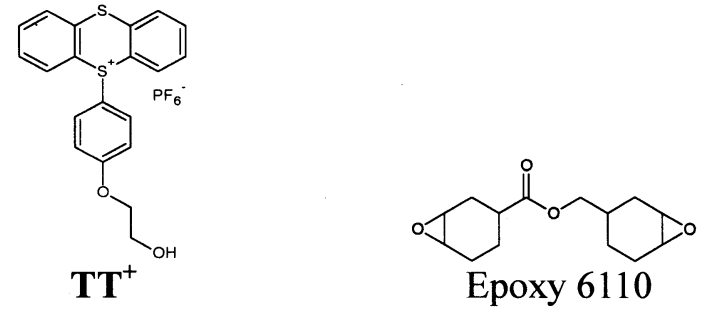<smiles>O=c1c2ccccc2sc2ccccc12</smiles>

TX<smiles>CC(C)c1cccc2c(=O)c3ccccc3sc12</smiles>

ITX

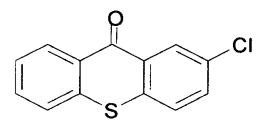

2CTX<smiles>c1ccc2c(c1)Nc1ccccc1S2</smiles>

$\mathrm{Ph}$<smiles>Cc1c2ccccc2cc2ccccc12</smiles>

9MA

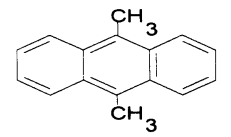

9,10DMA

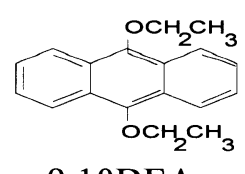

9,10DEA
Scheme 1. Compounds used in this study.

The conversion of the epoxy groups is calculated by the following equation:

$$
\text { Conversion }(\%)=\frac{\left(A_{750 \mathrm{am}^{-1}}\right)_{0}-\left(A_{750 \mathrm{~cm}^{-1}}\right)_{t}}{A_{750 \mathrm{~cm}^{-1}}}
$$

where $\left(\mathrm{A}_{750 \mathrm{~cm}^{-1}}\right)_{0}$ and $\left(\mathrm{A}_{750 \mathrm{~cm}^{-1}}\right)_{\mathrm{t}}$ represent respectively the areas of peak at the $750 \mathrm{~cm}^{-1}$ band to the initial time at beginning of the reaction and at time $t$, respectively. The rate of polymerization reaction $(R p)$ at time $t$ can be calculated by the following equation:

$$
R_{p}=\left[M_{0}\right] \frac{\left(A_{750 \mathrm{~cm}^{-1}}\right)_{0}-\left(A_{750 \mathrm{~cm}^{-1}}\right)_{t}}{t_{2}-t_{1}} * 100
$$

where $\left[\mathrm{M}_{0}\right]$ is the original concentration of epoxy groups. Values reported in this paper correspond to $\mathrm{Rp}{ }^{\prime}=\mathrm{Rp} /\left[\mathrm{M}_{0}\right] \mathrm{x} 100$. In most systems, Rp' reaches its maximum value in the 10 to $30 \%$ conversion range.

\subsection{Electrochemical measurements}

The redox potentials were measured in acetonitrile by cyclic voltammetry with tetrabutylammonium hexafluorophosphate 0.1 $M$ as supporting electrolyte. The working 
electrode was a platinum disk and the reference a saturated calomel electrode in methanol (SCE). Ferrocene was used as a standard and the potentials determined from the half peak potential were referred to the reversible formal potential $(+0.44 \mathrm{~V} / \mathrm{SCE})[10,11]$.

\section{Results and discussion}

3.1. Photopolymerization of epoxide resin

Figure 1. shows typical profiles of photopolymerization obtained with $\mathrm{R} 1$ resin. As can be seen, $\mathrm{TT}^{+}$is an effective photoinitiator, with a Rp' value of about 3 units and a final conversion of about $42 \%$.

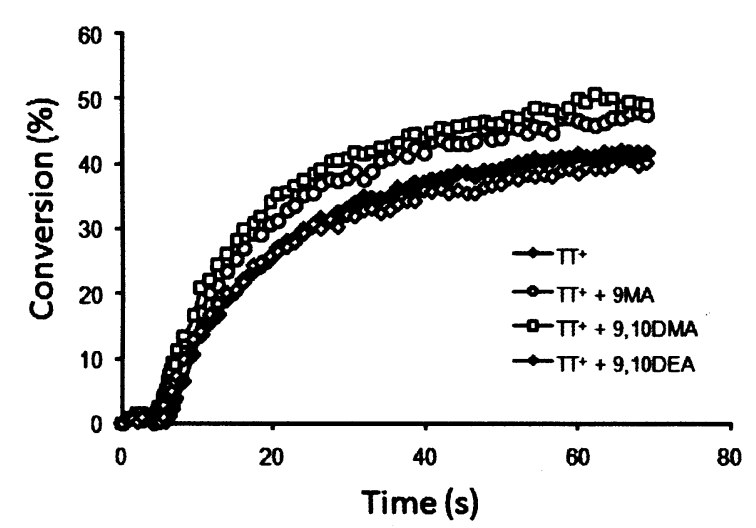

Figure 1. Photopolymerization profiles of $\mathrm{R} 1$ in the presence of $\mathrm{TT}^{+}$sensitized by anthracence derivatives.

The addition of some sensitizers significantly improves both the rate of polymerization and the final conversion, showing that the sensitization process is effective for $\mathrm{TT}^{+}$. However, the behavior of the sensitizers differs depending on their structure, as shown in Table 1.

The best sensitizer is clearly $\mathrm{Ph}$, for which Rp' was increased by a factor of 2 and an increase of about $25 \%$ was found for the final conversion. Thioxanthone derivatives also improves Rp' and the conversion, although in a lower extent. Finally, anthracene derivatives do not affect significantly the photopolymerization process.

\subsection{Decomposition mechanism}

The decomposition of $\mathrm{TT}^{+}$through direct excitation, in the absence of any sensitizer, was already reported $[5,12]$. This mechanism shows that the photolysis of thianthrenium salts can occur via two pathways: a) a cleavage process occurs in the excited state of $\mathrm{TT}^{+}$that generates the thianthrene
Table 1. Photosensitization of Esacure 1187 in the presence Epoxy 6110

\begin{tabular}{|c|c|c|}
\hline Samples & $\mathrm{Rp}^{\prime}\left(\mathrm{s}^{-1}\right)$ & $\begin{array}{c}\text { Conversion } \\
(\%)\end{array}$ \\
\hline $\mathrm{TT}^{+}$ & 2.98 & 41.6 \\
\hline $\mathrm{TT}^{+}+\mathrm{Ph}$ & 5.52 & 52.0 \\
\hline $\mathrm{TT}^{+}+2 \mathrm{CTX}$ & 3.52 & 48.1 \\
\hline $\mathrm{TT}^{+}+\mathrm{TX}$ & 3.26 & 55.8 \\
\hline $\mathrm{TT}^{+}+\mathrm{ITX}$ & 3.09 & 46.3 \\
\hline $\mathrm{TT}^{+}+9 \mathrm{MA}$ & 3.02 & 47.5 \\
\hline $\mathrm{TT}^{+}+9,10 \mathrm{DMA}$ & 2.22 & 50.1 \\
\hline $\mathrm{TT}^{+}+9,10 \mathrm{DEA}$ & 2.50 & 39.6 \\
\hline
\end{tabular}

cation radical and an aryl radical. In this case, fragmentation-recombination reactions produce a strong Brönsted acid, through the interaction with a proton source such the monomer (M), impurity, or solvent. b) a cation-radical-radical pair is generated through the cleavage of the carbon-sulfur bonds of the thianthrene ring. The proximity of the radicals that are linked by other covalent bonds facilitates the recombination to the initial state of the salt, which results in the decrease of the quantum yield of acid release (Scheme 2).

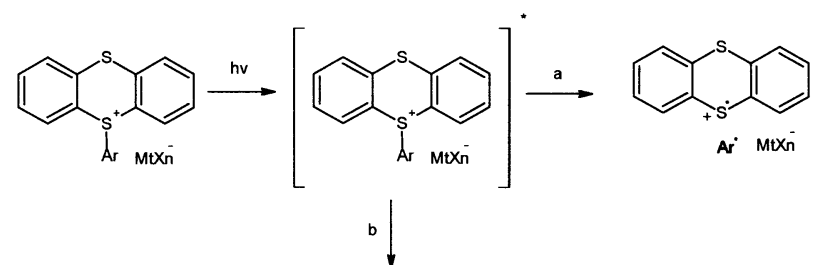<smiles>N#Cc1ccccc1Sc1ccccc1</smiles><smiles>Cc1cccc2c1sc1ccccc1sc1nc(N)ccc12</smiles>

Scheme 2. Direct excitation of $\mathrm{TT}^{+}$

\subsection{Photosensitization mechanism}

In the present case, the fragmentation process occurs after an electron transfer reaction from the excited sensitizer to $\mathrm{TT}^{+}$. If the back electron transfer process does not take place, the radical cation formed initiates the reaction. Therefore, the energetic of the photoinduced electron transfer governs the efficiency of the process. 
The $\Delta \mathrm{G}$ of the reaction can be estimated using the Rehm-Weller equation:

$$
\Delta G=f_{c}\left(E_{1 / 2}^{o x}-E_{1 / 2}^{r e d}\right)-E\left(P S^{*}\right)
$$

where, $E_{1 / 2}^{o x}$ and $E_{1 / 2}^{\text {red }}$ represent the halfwave potentials (in V) of the oxidation of PS and the reduction of onium salt, respectively. $\mathrm{E}\left(\mathrm{PS}^{*}\right)$ is the excitation energy of PS (in kJ.mol ${ }^{-1}$ ) and $f_{c}$ is the conversion factor. $\mathrm{E}\left(\mathrm{PS}^{*}\right)$ is the energy of the reacting excited state of the photosensitizer, i.e. either the singlet $\left(\mathrm{E}_{\mathrm{S}}\right)$ or the triplet $\left(\mathrm{E}_{\mathrm{T}}\right)$ state.

It should be noted that due to the viscosity of the solvent the rate constant of electron transfer is diffusion controlled. Therefore, the efficiency of the process is higher when the reaction proceeds from the triplet state of the sensitizer than from the singlet state (Table 2), and should be related to the $\Delta \mathrm{G}_{\mathrm{T}}$ for the electron transfer from the triplet state.

Table 2. Energetics of the electron transfer reaction.

\begin{tabular}{|c|c|c|c|}
\hline sensitizer & $\begin{array}{c}E_{1 / 2}^{o x} \\
(\mathrm{~V} / \mathrm{SCE})\end{array}$ & $E\left(P S^{*}\right)(\mathrm{Kj} / \mathrm{mol})$ & $\Delta G(\mathrm{Kj} / \mathrm{mol})$ \\
\hline $\mathrm{Ph}$ & $0.56^{\mathrm{a}}$ & $\mathrm{E}_{\mathrm{T}}=239^{\mathrm{b}}$ & $\Delta \mathrm{G}_{\mathrm{T}}=-50.7$ \\
\hline $2 \mathrm{CTX}$ & $1.86^{\mathrm{a}}$ & $\mathrm{E}_{\mathrm{T}}=281^{\mathrm{c}}$ & $\Delta \mathrm{G}_{\mathrm{T}}=32.7$ \\
\hline $\mathrm{TX}$ & $1.68^{\mathrm{a}}$ & $\mathrm{E}_{\mathrm{T}}=271^{\mathrm{h}}$ & $\Delta \mathrm{G}_{\mathrm{T}}=25.3$ \\
\hline ITX & $1.65^{\mathrm{a}}$ & $\mathrm{E}_{\mathrm{T}}=262^{\mathrm{d}}$ & $\Delta \mathrm{G}_{\mathrm{T}}=31.4$ \\
\hline 9MA & $1.13^{\mathrm{a}}$ & $\mathrm{E}_{\mathrm{T}}=173^{\mathrm{f}}$ & $\Delta \mathrm{G}_{\mathrm{T}}=70.2$ \\
\hline 9,10DMA & $1.09^{\mathrm{e}}$ & $\mathrm{E}_{\mathrm{T}}=173^{\mathrm{g}}$ & $\Delta \mathrm{G}_{\mathrm{S}}=66.4$ \\
\hline 9,10DEA & $0.88^{\mathrm{e}}$ & $\mathrm{E}_{\mathrm{T}}=173^{\mathrm{g}}$ & $\Delta \mathrm{G}_{\mathrm{S}}=46.1$ \\
\hline
\end{tabular}

a) This work; b) Ref. 13; c) Ref. 14; d) Ref. 15; e) Ref. 16 ; f) Ref. 18 ; g) estimated as similar to that of 9MA; h) Ref. 17.

These values allow the evaluation of $\Delta \mathrm{G}$ using $E_{1 / 2}^{\text {red }}=-1.39 \mathrm{~V} / \mathrm{SCE}$ for $\mathrm{TT}^{+}$. From the results, it can be seen that $\Delta \mathrm{G}$ is strongly exergonic for $\mathrm{Ph}$, slightly exergonic for thioxanthone derivatives and endergonic for the anthracene derivatives, in good agreement with the photopolymerization efficiencies. This confirm the reaction pathway for the sensitized decomposition of thianthrenium salts.

\section{Conclusion}

The photosensitization mechanism of a thianthrenium salt by excited electron donor was discussed. The photopolymerization efficiency increases with increasing the energetic of the photoinduced electron transfer from the sensitizer to the onium salt.

\section{References}

1. P. Pappas, M. G. Tilley, B. C. Pappas, J. Photochem. Photobiol. A, 2 (2003) 161.

2. W. G. Kim, H. K. Ann, H. W. Lee, S. H. Kim, J.V. Crivello, Opt. Materials, 21(2003) 343.

3. J. V. Crivello, J. Polym. Sci. Pol. Chem, 23(1999) 4241.

4. J. V. Crivello, J. L. Lee, Polym. Bull, 4 (1986) 243.

5. J.V. Crivello, J. Ma, F. Jiang, J. Polym. Sci. Pol. Chem., 20 (2002) 3465.

6. T. Kitamura, K. Morizane, H. Taniguchi, Tetrahedron. Lett., 29 (1997) 5157.

7. X. Wang, F.D. Saeva, J.A. Kampmeier, J. Am. Chem. Soc., 18 (1999) 4364.

8. C. Decker, K. Moussa, Macromolecules, 22 (1989) 4455.

9. M. Dossot, H. Obeid, X. Allonas, P. Jacques, J.P. Fouassier, A. Merlin, J. App. Pol. Sci. 92 (2004) 1154.

10. X. Allonas, J.P. Fouassier, M. Kaji, Y. Murakami, Photochem. Photobiol. Sci. 2 (2003) 224.

11. W.C. Barrette, H.W. Johnson, D.T. Sawyer, Anal. Chem. 56 (1984) 1890.

12. C. Selvaraju, A. Sivakumar, P. Ramamurthy, $J$. Photochem. Photobiol. A, 3 (2001) 213.

13. W. Schnabel, Macromol. Rap. Com., 21 (2000) 628.

14. K. Annett, M. Uwe, T. Knut, J.P. Fouassier, F. Morlet-Savary, J. Photochem. Photobiol. A, 110 (1997) 115.

15. G. Pohlers, J. Scaiano, E. Step, R. Sinta, J. Am. Chem. Soc. 121 (1999) 6167.

16. K. Ohkubo, R. Iwata, S. Miyazaki, T. Kojima, S. Fukuzumi, Org. Lett., 8 (2006) 6079.

17. X. Allonas, C. Ley, C. Bibaut, P. Jacques, J.P. Fouassier, Chem. Phys. Lett., 322 (2000) 483.

18. S.L. Murov, G.L. Hug, I. Carmichael, Handbook of Photochemistry, Marcel Dekker Inc, 1993. 